\title{
Ligand-Centered Triplet Diradical Supported by a Binuclear Palladium(II) Dipyrrindione
}

\author{
Clayton J. Curtis, Andrei V. Astashkin, Jeanet Conradie, Abhik Ghosh,* and Elisa Tomat*
}

Cite This: Inorg. Chem. 2021, 60, 12457-12466

Read Online

ABSTRACT: Oligopyrroles form a versatile class of redox-active ligands and electron reservoirs. Although the stabilization of radicals within oligopyrrolic $\pi$ systems is more common for macrocyclic ligands, bidentate dipyrrindiones are emerging as compact platforms for one-electron redox chemistry in transitionmetal complexes. We report the synthesis of a bis(aqua) palladium(II) dipyrrindione complex and its deprotonation-driven dimerization to form a hydroxo-bridged binuclear complex in the presence of water or triethylamine. Electrochemical, spectroelectrochemical, and computational analyses of the binuclear complex indicate the accessibility of two quasi-reversible ligand-centered reduction processes. The product of a two-electron chemical reduction by cobaltocene was isolated and characterized. In the

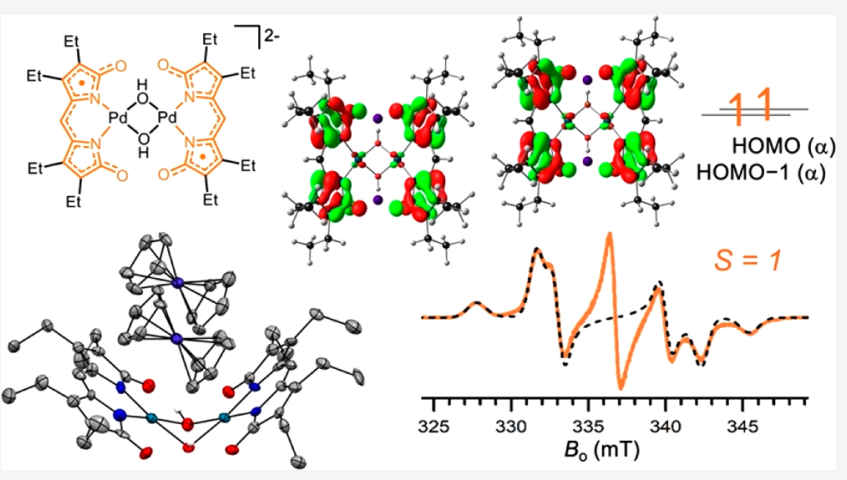
solid state, this cobaltocenium salt features a folded dianionic complex that maintains the hydroxo bridges between the divalent palladium centers. X-band and Q-band EPR spectroscopic experiments and DFT computational analysis allow assignment of the dianionic species as a diradical with spin density almost entirely located on the two dipyrrindione ligands. As established from the EPR temperature dependence, the associated exchange coupling is weak and antiferromagnetic $(J \approx-2.5 \mathrm{~K})$, which results in a predominantly triplet state at the temperatures at which the measurements have been performed.

\section{INTRODUCTION}

Coordination compounds of redox-active ligands, in which oxidizing and/or reducing equivalents can be stored on the ligand $\pi$ system, have generated broad interest owing to their potential applications in areas including homogeneous catalysis, ${ }^{1}$ molecular magnetism, ${ }^{2}$ photovoltaic devices, ${ }^{3}$ and quantum information processing (e.g., spin qubits). ${ }^{4}$ Macrocyclic oligopyrroles, ${ }^{5}$ such as porphyrins, corroles, ${ }^{6}$ and several expanded porphyrinoids, ${ }^{7}$ are well-studied examples of redoxactive ligands, and their ability to host unpaired spins has been investigated extensively. Besides macrocyclic structures, early examples of linear oligopyrrolic radicals in metal complexes were found in the study of bilindiones (Chart 1a), ${ }^{8,9}$ but more recent reports highlighted the formation of stable ligand-based radicals in metal complexes of tetradentate bis(phenolate)dipyrrins (Chart 1b), ${ }^{10,11}$ bis(2-aminophenyl)-dipyrrins, ${ }^{12}$ and diimino-dipyrrins, ${ }^{13}$ as well as tridentate tripyrrindione (Chart 1c) ${ }^{14-18}$ and dihydrazonopyrrole ${ }^{19}$ scaffolds.

Contracting the conjugated $\pi$ system from tetradentate to tridentate to bidentate oligopyrroles, the observation of stable ligand-centered radicals becomes less common. Within the large family of bidentate dipyrrins, ${ }^{20}$ ligand-centered redox chemistry is observed with varying degrees of success depending on substituents; ${ }^{21}$ however, the bidentate dipyrrin system has not been generally employed for the stabilization of unpaired electrons. In contrast, the dipyrrin-1,9-dione motif
Chart 1. Metal Complexes of Tetradentate ( $a$ and $b$ ) and Tridentate (c) Pyrrolic Ligands Featuring Ligand-Based Radicals

(a)

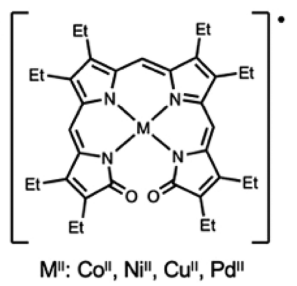

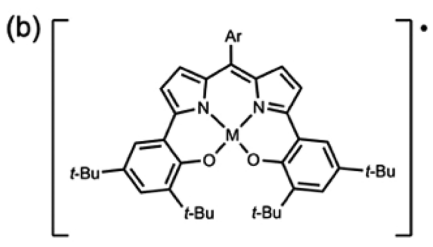

(c)

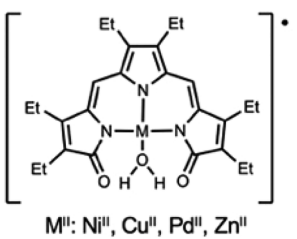

Received: June 3, 2021

Published: August 4, 2021 
serves as a compact dipyrrolic platform to host ligand-centered radicals. ${ }^{22-24}$ This bidentate ligand could therefore extend the diverse applications of dipyrrin complexes, ranging from fluorescent sensors to catalysis and metal-organic frameworks, to take advantage of one-electron redox chemistry and a variety of spin states.

Historically referred to as propentdyopents, the naturally occurring dipyrrindione pigments result from the oxidative metabolism of heme. ${ }^{25}$ The first dipyrrindione complexes were isolated from products of degradation of bilindione complexes; ${ }^{9,26}$ however, we recently employed the $\mathrm{Hpdp} \cdot \mathrm{MeOH}$ adduct for the preparation of homoleptic ${ }^{22}$ and heteroleptic $^{23,24}$ compounds (Chart 2). Because of the availability

Chart 2. Tetraethyl Propentdyopent-Methanol Adduct (a) and Reported Complexes $(b-d)$ (a)<smiles>CCC1=C(CC)/C(=C/C2(C)NC(=O)C(CC)=C2CC)NC1=O</smiles>

$\mathrm{Hpdp} \cdot \mathrm{MeOH}$

(c)

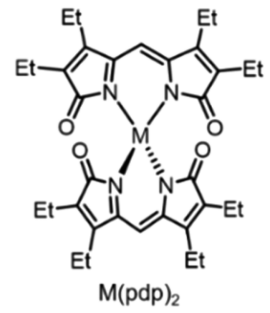

(b)<smiles></smiles>

(d)

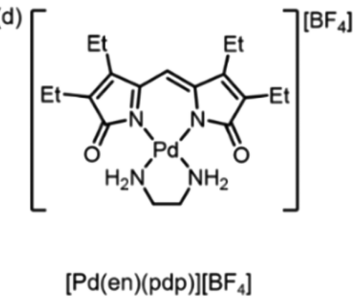

M: Co", Ni", Cu", Zn"

\section{RESULTS AND DISCUSSION}

Synthesis and Chemical Characterization. The tetraethyl dipyrrindione methanol adduct ( $\mathrm{Hpdp} \cdot \mathrm{MeOH}$, Chart 2a) was added to a dichloromethane solution of palladium(II) acetylacetonate in the presence of $\mathrm{HBF}_{4}$, which facilitated the dissociation of the bidentate $\mathrm{acac}^{-}$ligands and their replacement with a higher-affinity ligand. ${ }^{33}$ This particular acid was also chosen so as to include the noncoordinating counterion $\mathrm{BF}_{4}^{-}$and facilitate crystallization. The reaction progress was accompanied by a color change from yellow to deep red over the course of 3-4 h at room temperature: in particular, we observed the gradual decrease of the single absorption band of $\mathrm{Hpdp} \cdot \mathrm{MeOH}$ at $280 \mathrm{~nm}$ and the growth of two main bands at 382 and $545 \mathrm{~nm}$, consistent with our previous reports on dipyrrindione complexes. ${ }^{22,24}$

In the course of our synthetic manipulations, we observed that exposing a dichloromethane solution of this red complex to an aqueous wash resulted in an immediate color change of the organic phase from red to blue. The absorption spectrum of the blue solution in $\mathrm{CH}_{2} \mathrm{Cl}_{2}$ presents a shift in the main bands to 372 and $585 \mathrm{~nm}$ (Figure 1 and Table S1), clearly indicating the formation of a different species.

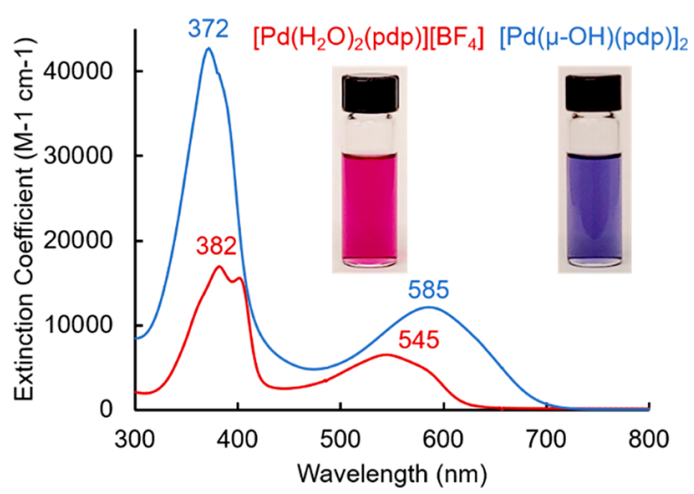

Figure 1. UV-visible absorption spectra of $\left[\mathrm{Pd}\left(\mathrm{H}_{2} \mathrm{O}\right)_{2}(\mathrm{pdp})\right]\left[\mathrm{BF}_{4}\right]$ (red) and $[\mathrm{Pd}(\mu-\mathrm{OH})(\mathrm{pdp})]_{2}$ (blue) in $\mathrm{CH}_{2} \mathrm{Cl}_{2}$.

The isolated red and blue complexes are diamagnetic, as determined by NMR spectroscopy. The ${ }^{1} \mathrm{H}$ NMR spectrum of the red complex (Figure S1) features $\mathrm{pdp}^{-}$resonances analogous to those in our previous reports. ${ }^{24}$ The corresponding ${ }^{13} \mathrm{C}$ NMR spectrum (Figure S2) featured only resonances attributed to the dipyrrindione framework, eliminating the possibility of a bound $\mathrm{acac}^{-}$ion. In addition, a sharp singlet integrating to four protons at $6.66 \mathrm{ppm}$ in the ${ }^{1} \mathrm{H}$ NMR spectrum suggested the presence of two coordinated aqua ligands bound to the metal center.

In the ${ }^{1} \mathrm{H}$ and ${ }^{13} \mathrm{C}$ NMR spectra of the blue complex (Figures S1 and S2), the resonances corresponding to the ligand framework were shifted slightly upfield relative to the red complex (e.g., $5.55 \mathrm{ppm}$ vs $5.87 \mathrm{ppm}$ for the meso-type proton). The most notable difference between the spectra was the disappearance of the $4 \mathrm{H}$ singlet at $6.66 \mathrm{ppm}$ and the appearance of a new singlet at $3.07 \mathrm{ppm}$, which integrated to one proton relative to the meso-type resonance. Because of the increased acidity of palladium-bound aqua ligands, we hypothesized a deprotonation and formation of a hydroxobridged species as previously observed in the case of diaqua palladium(II)-BINAP complexes, which readily formed hydroxo dimers upon treatment with $4 \AA$ molecular sieves in 
acetone. ${ }^{34}$ Conclusive data on the structure of both complexes in the solid state were then obtained by X-ray crystallography (see Table S2 for collection parameters).

The crystal structure of the red complex confirmed the coordination of a single $\mathrm{pdp}^{-}$ligand to the palladium(II) center also featuring two aqua ligands and a tetrafluoroborate counteranion in close vicinity (Figures 2 and S3). The

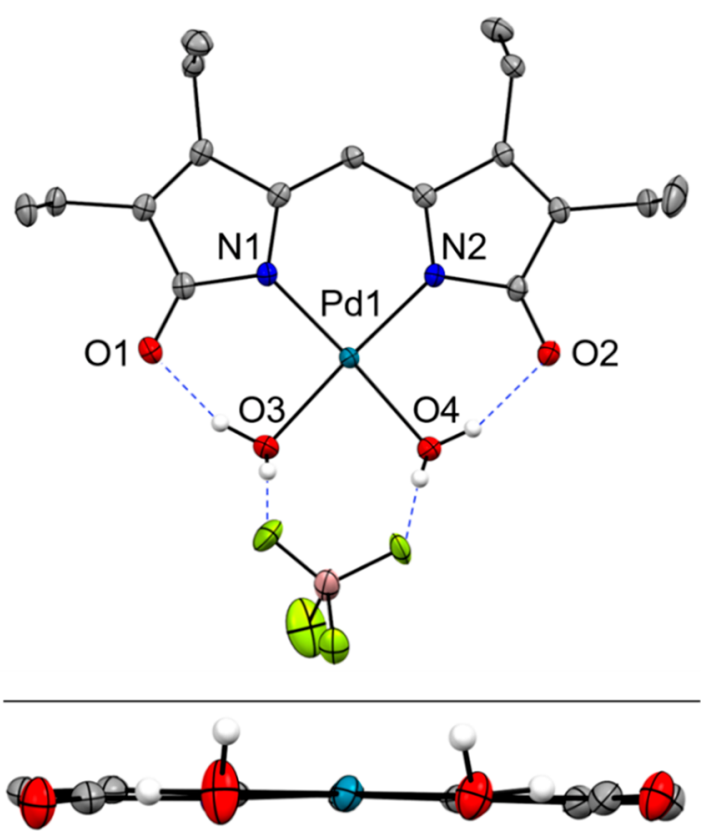

Figure 2. Crystal structure of $\left[\mathrm{Pd}\left(\mathrm{H}_{2} \mathrm{O}\right)_{2}(\mathrm{pdp})\right]\left[\mathrm{BF}_{4}\right]$ showing a partial labeling scheme. Carbon-bound hydrogen atoms are omitted for clarity. Non-hydrogen atoms are displayed as thermal displacement ellipsoids set at the $50 \%$ probability level. In the side view (bottom panel), ethyl substituents were removed for clarity. CCDC: 2077676.

coordination geometry of the palladium(II) center is square planar, and the $\mathrm{Pd}-\mathrm{N} / \mathrm{O}$ bond distances (ranging from $1.984(3)$ to $2.060(3) \AA)$ and angles $\left(84.3-92.6^{\circ}\right)$ are consistent with those in analogous palladium(II) dipyrrinato complexes $^{35,36}$ and heteroleptic dipyrrindione palladium(II) structures. $^{24}$ The $\mathrm{pdp}^{-}$ligand is fully coplanar with the palladium(II) coordination plane, and the bond lengths in the dipyrrindione framework (Table S3) indicate two terminal carbonyl groups at the pyrrolic $\alpha$-positions ( $\mathrm{C}-\mathrm{O}, 1.223(3)$ and $1.226(3) \AA$ ). As previously reported for dipyrrindione $e^{24}$ and tripyrrindione ${ }^{14,15,18}$ complexes, these carbonyl groups serve as effective hydrogen-bonding acceptors: the aqua ligands are engaged in hydrogen-bonding interactions with both the propentdyopent scaffold and the tetrafluoroborate anions, and all aqua hydrogens were located on the Fourier map during structure refinement.

The crystal structure of the blue complex (Figures 3 and S4) presents a coordination dimer, wherein the two palladium(II) centers are each bound to one dipyrrindione and two bridging hydroxo ligands. In contrast to the red complex [Pd$\left.\left(\mathrm{H}_{2} \mathrm{O}\right)_{2}(\mathrm{pdp})\right]^{+}$, the blue species $[\mathrm{Pd}(\mu-\mathrm{OH})(\mathrm{pdp})]_{2}$ is neutral, and the two $\mathrm{pdp}^{-}$ligands are slightly canted with a minor curvature of the rigid dipyrrolic scaffold. The $\mathrm{Pd}-\mathrm{N} / \mathrm{O}$ bond distances $(1.979(3)-2.014(3) \AA)$ are similar to those in $\left[\mathrm{Pd}\left(\mathrm{H}_{2} \mathrm{O}\right)_{2}(\mathrm{pdp})\right]\left[\mathrm{BF}_{4}\right]$, and the bond lengths in the dipyrrolic framework remain largely unchanged upon dimeri-
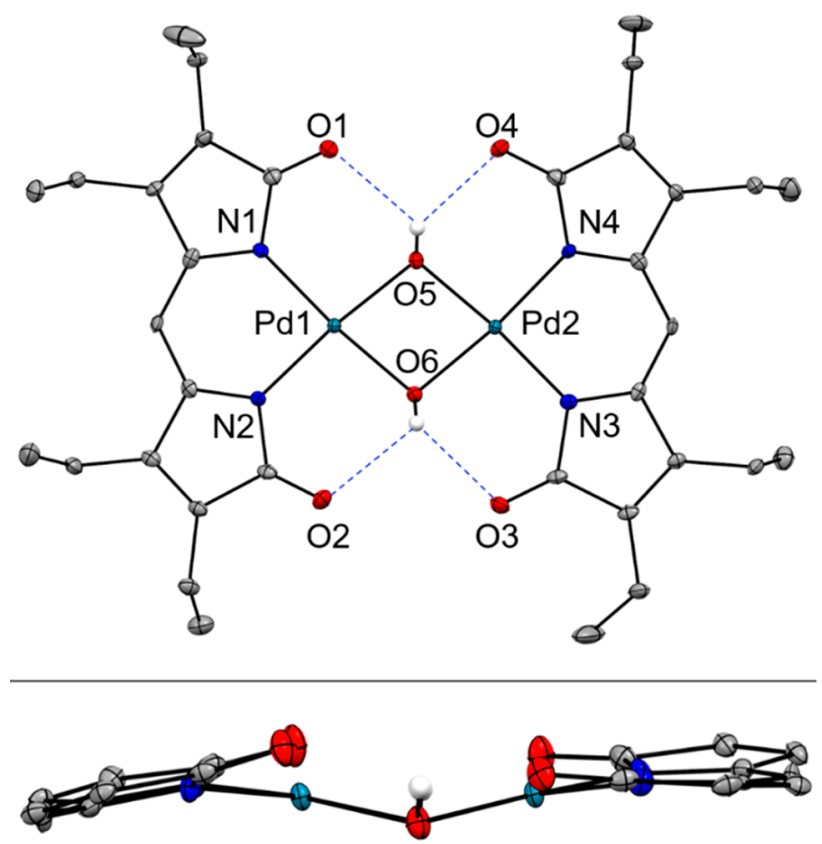

Figure 3. Crystal structure of $[\mathrm{Pd}(\mu-\mathrm{OH})(\mathrm{pdp})]_{2}$ showing a partial labeling scheme. Carbon-bound hydrogen atoms are omitted for clarity. Non-hydrogen atoms are displayed as thermal displacement ellipsoids set at the $50 \%$ probability level. In the side view (bottom panel), ethyl substituents were removed for clarity. CCDC: 2077677.

zation (Table S4), indicating no change in the redox state of either the palladium(II) center or the ligand scaffold. The hydrogen atoms of the $\mu$-hydroxo ligands are engaged in hydrogen-bonding interactions with two carbonyl oxygen atoms of the dipyrrindione ligands (Figure 3).

The solid-state analysis of $\left[\mathrm{Pd}\left(\mathrm{H}_{2} \mathrm{O}\right)_{2}(\mathrm{pdp})\right]\left[\mathrm{BF}_{4}\right]$ and $[\mathrm{Pd}(\mu-\mathrm{OH})(\mathrm{pdp})]_{2}$ is consistent with the observed differences between their respective ${ }^{1} \mathrm{H}$ NMR spectra in $\mathrm{CDCl}_{3}$ solutions: the bound aqua ligands in the $\left[\mathrm{Pd}\left(\mathrm{H}_{2} \mathrm{O}\right)_{2}(\mathrm{pdp})\right]^{+}$complex (i.e., $4 \mathrm{H}$ at $6.66 \mathrm{ppm}$ ) are deprotonated in aqueous conditions to form the dimeric complex $[\mathrm{Pd}(\mu-\mathrm{OH})(\mathrm{pdp})]_{2}$ featuring two $\mu$-hydroxo bridges (i.e., $2 \mathrm{H}$ at $3.07 \mathrm{ppm}$ ). The upfield shift of the $\mathrm{OH}$ resonance in the dimer is consistent with weaker hydrogen bonds, possibly owing to the less favorable orientation of the hydroxo bridges within the complex. For comparison, the aqua protons in the cationic $\mathrm{Pd}(\mathrm{II})$ tripyrrindione appear at $8.52 \mathrm{ppm}$, indicative of more effective hydrogen-bonding interactions. ${ }^{14}$

The interconversion between $\left[\mathrm{Pd}\left(\mathrm{H}_{2} \mathrm{O}\right)_{2}(\mathrm{pdp})\right]\left[\mathrm{BF}_{4}\right]$ and the bis- $\mu$-hydroxo dimer $[\mathrm{Pd}(\mu-\mathrm{OH})(\mathrm{pdp})]_{2}$ (Scheme 1$)$ could be monitored by optical absorption spectroscopy in organic solvents. When starting with a solution of $\left[\mathrm{Pd}\left(\mathrm{H}_{2} \mathrm{O}\right)_{2}(\mathrm{pdp})\right]-$ $\left[\mathrm{BF}_{4}\right]\left(75 \mu \mathrm{M}, \mathrm{CH}_{2} \mathrm{Cl}_{2}\right)$, the addition of triethylamine resulted

Scheme 1. Reversible Deprotonation and Dimerization of $\left[\operatorname{Pd}\left(\mathrm{H}_{2} \mathrm{O}\right)_{2}(\mathrm{pdp})\right]^{+}$

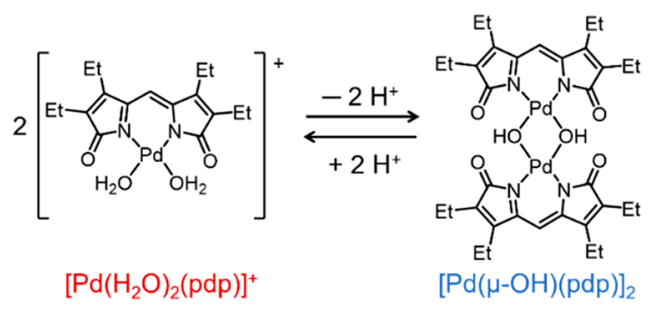


in the rapid consumption of the diaqua complex $\left(\lambda_{\max }=545\right.$ $\mathrm{nm})$ and formation of the $\mu$-hydroxo dimer $\left(\lambda_{\max }=585 \mathrm{~nm}\right)$, with saturation reached at $\sim 2.0$ equiv of base (Figure S5). Conversely, the addition of trifluoroacetic acid (TFA, 2 equiv) to a solution of $[\mathrm{Pd}(\mu-\mathrm{OH})(\mathrm{pdp})]_{2}(51 \mu \mathrm{M}, 95: 5(\mathrm{v} / \mathrm{v})$ $\left.\mathrm{CH}_{2} \mathrm{Cl}_{2}: \mathrm{CH}_{3} \mathrm{OH}\right)$ resulted in the rapid shift of the lowerenergy maximum from 585 to $545 \mathrm{~nm}$, confirming the formation of the diaqua monomer complex (Figure S5). The addition of a small amount of methanol to the solvent mixture (i.e., $5 \% \mathrm{CH}_{3} \mathrm{OH}$ in $\mathrm{CH}_{2} \mathrm{Cl}_{2}$ ) facilitated proton transfer in solution. Under these acidic conditions, however, partial demetalation was observed, particularly upon addition of more than 2.0 equiv of acid.

Overall, these experiments indicated the formation of a diaqua $\mathrm{Pd}(\mathrm{II})$ dipyrrindione complex that is similar to the analogous complexes of primary amines, ${ }^{24}$ in which the square planar coordination is stabilized by hydrogen-bonding interactions between ligands. The metal-bound aqua ligands, however, are quite acidic and undergo facile deprotonation concurrently with the formation of a bis $(\mu-\mathrm{OH})$ dimeric complex. A pronounced color change of the solution from red to blue accompanies the conversion of the diaqua complex to the bis-hydroxo species through deprotonation and dimerization.

DFT Analysis of $\left[\mathrm{Pd}\left(\mathrm{H}_{2} \mathrm{O}\right)_{2}(\mathrm{pdp})\right]^{+}$and $[\mathrm{Pd}(\mu-\mathrm{OH})-$ (pdp) $]_{2}$. Density functional theory (DFT) calculations have been employed in one of our laboratories to describe ligand noninnocence, ${ }^{37}$ metal versus ligand-centered oxidation and reduction, ${ }^{38,39}$ and aromaticity ${ }^{40,41}$ in oligopyrrolic systems. Herein, all-electron dispersion-corrected scalar-relativistic DFT (OLYP-D3) calculations with large STO-TZ2P basis sets were deployed to contextualize the experimental results on $[\mathrm{Pd}$ $\left.\left(\mathrm{H}_{2} \mathrm{O}\right)_{2}(\mathrm{pdp})\right]^{+}$and $[\mathrm{Pd}(\mu-\mathrm{OH})(\mathrm{pdp})]_{2}$.

Although the optimized bond distances and angles were generally in good agreement with experimental values (Table S5), a folded conformation was found for the binuclear complex (Figure S6), at odds with an essentially planar geometry in the solid state (Figure 3 ). The Pd-Pd distance $(2.685 \AA)$ in the folded conformation was shorter than the sum of the van der Waals radii (3.26 $\AA$ ), indicating a potential bonding interaction. The MOs for this $C_{2 v}$ geometry show filled bonding and antibonding orbitals involving the $\operatorname{Pd}\left(\mathrm{d}_{z}{ }^{2}\right)$ orbitals (Figure S7) typical of $\mathrm{d}^{8}-\mathrm{d}^{8}$ interactions, ${ }^{30,42}$ in which an overall weakly bonding character results from mixing with the metal $s$ and $p_{z}$ orbitals and is a potential driving force for this conformation. Although the occurrence of this folded structure in solution cannot be ruled out, packing effects in the crystalline solid are likely responsible for the rather planar structure observed in the solid state (Figure 3).

Because the folding of the dimer structure is likely to be soft mode with relatively little impact on intramolecular bonding, we chose to carry out further analysis with a symmetryconstrained $D_{2 \mathrm{~h}}$ (i.e., unfolded) model, $[\mathrm{Pd}(\mu-\mathrm{OH})(\mathrm{pdp}-\mathrm{h})]_{2}$, with unsubstituted $\mathrm{pdp}^{-}$ligands. An examination of the HOMO and LUMO of the monomeric and dimeric complexes provided a plausible explanation for the $40 \mathrm{~nm}$ spectral redshift of the lowest-energy band in the UV-vis spectrum of the latter. Broadly speaking, the HOMOs of both the monomeric and dimeric complexes show substantial mixing of $\mathrm{Pd}(4 \mathrm{~d})$ and $\operatorname{pdp}(\pi)$-based orbitals (Figures 4 and S8). The LUMOs, in contrast, are almost purely pdp-based. Compared to $[\mathrm{Pd}$ $\left.\left(\mathrm{H}_{2} \mathrm{O}\right)_{2}(\mathrm{pdp}-\mathrm{h})\right]^{+}$, the HOMO of $[\mathrm{Pd}(\mu-\mathrm{OH})(\mathrm{pdp}-\mathrm{h})]_{2}$ exhibits increased destabilizing filled-filled $\operatorname{Pd}\left(\mathrm{d}_{\pi}\right)-\mathrm{O}\left(\mathrm{p}_{z}\right)$

\section{$\left[\mathrm{Pd}\left(\mathrm{H}_{2} \mathrm{O}\right)_{2}(\mathrm{pdp}-\mathrm{h})\right]^{+}$}
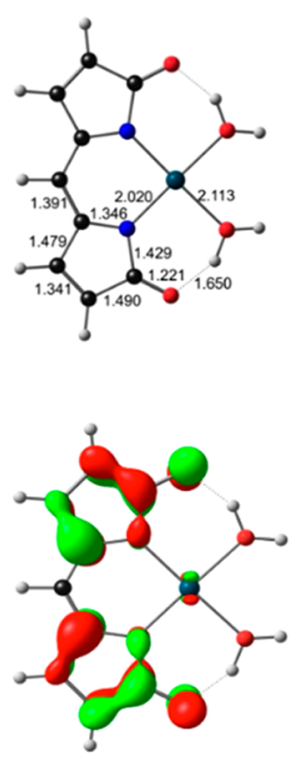

LUMO, $\mathrm{a}_{2}$

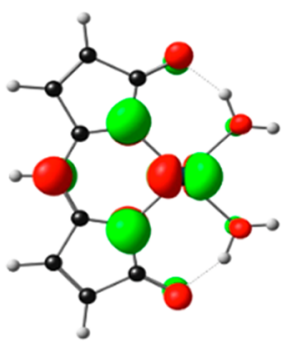

$\mathrm{HOMO}, \mathrm{b}_{1}$
$[\mathrm{Pd}(\mu-\mathrm{OH})(\mathrm{pdp}-\mathrm{h})]_{2}$
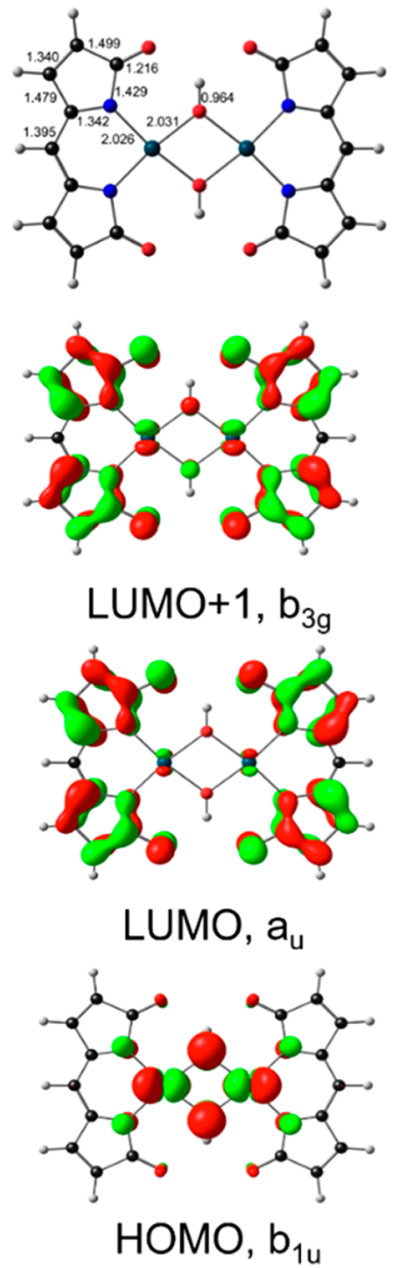

Figure 4. Frontier Kohn-Sham MOs of the simplified model complexes $\left[\mathrm{Pd}\left(\mathrm{H}_{2} \mathrm{O}\right)_{2}(\mathrm{pdp}-\mathrm{h})\right]^{+}\left(\mathrm{C}_{2 v}\right)$ and $[\mathrm{Pd}(\mu-\mathrm{OH})(\mathrm{pdp}-\mathrm{h})]_{2}$ $\left(D_{2 h}\right)$ with selected bond lengths of optimized geometries $(\AA)$.

antibonding interactions, which translate to a lower HOMO-LUMO gap and thus to the observed spectral redshift.

Characterization of Ligand-Based Reduction Products. The electrochemical profiles of $\left[\mathrm{Pd}\left(\mathrm{H}_{2} \mathrm{O}\right)_{2}(\mathrm{pdp})\right]\left[\mathrm{BF}_{4}\right]$ and $[\mathrm{Pd}(\mu-\mathrm{OH})(\mathrm{pdp})]_{2}$ were investigated by cyclic voltammetry in $\mathrm{CH}_{2} \mathrm{Cl}_{2}$, with potentials referenced to the ferrocenium/ferrocene redox couple $\left(\mathrm{Fc}^{+} / \mathrm{Fc}\right)$. The voltammogram of $\left[\mathrm{Pd}\left(\mathrm{H}_{2} \mathrm{O}\right)_{2}(\mathrm{pdp})\right]\left[\mathrm{BF}_{4}\right]$ displayed an irreversible reduction event at $-0.431 \mathrm{~V}$ (Figure 5, left panel). Spectroelectrochemical analysis of this event showed initial formation of absorption bands consistent with a dipyrrindione radical (Figure S9) as observed for other heteroleptic complexes. ${ }^{24}$ However, this species was short-lived, and a rapid overall decrease in absorbance intensity indicated degradation. In contrast, the cyclic voltammogram of $[\operatorname{Pd}(\mu$ $\mathrm{OH})(\mathrm{pdp})]_{2}$ presented two quasi-reversible reduction events with half-wave potentials at $-0.953 \mathrm{~V}\left(\Delta E_{\mathrm{p}}=84 \mathrm{mV}\right)$ and $-1.134 \mathrm{~V}\left(\Delta E_{\mathrm{p}}=86 \mathrm{mV}\right)$ (Figure 5, right panel) (Figures $\mathrm{S} 10$ and S11). The cathodic shift of these potentials relative to that of the diaqua precursor (see above) is attributed to the cationic nature of the latter, which is more easily reduced. ${ }^{24}$ Overall, the electrochemical profile of $[\mathrm{Pd}(\mu-\mathrm{OH})(\mathrm{pdp})]_{2}$ is consistent 


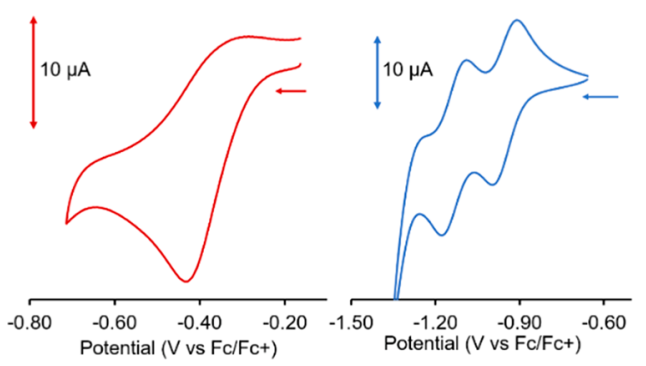

Figure 5. Cyclic voltammograms of $\left[\mathrm{Pd}\left(\mathrm{H}_{2} \mathrm{O}\right)_{2}(\mathrm{pdp})\right]\left[\mathrm{BF}_{4}\right]$ (left) and $[\mathrm{Pd}(\mu-\mathrm{OH})(\mathrm{pdp})]_{2}$ (right) at a glassy carbon electrode in $\mathrm{CH}_{2} \mathrm{Cl}_{2}$ with $\left(\mathrm{NBu}_{4}\right)\left(\mathrm{PF}_{6}\right)$ as a supporting electrolyte. Data collected at a $100 \mathrm{mV} \mathrm{s}^{-1}$ scan rate using a $\mathrm{Ag} / \mathrm{AgCl}$ pseudoreference electrode and a Pt wire auxiliary electrode.

with two sequential ligand-centered reductions. The relatively small difference in the two half-wave potentials $(181 \mathrm{mV})$ is suggestive of slight delocalization of the first reducing equivalent over the two ligands, corresponding to class II in the Robin-Day classification of mixed-valence compounds. ${ }^{43}$ Alternatively, assuming localized ligand reductions, the shift of the second reduction potential could be attributed to solvation effects of the monoanionic species as in the homoleptic propentdyopent complexes. ${ }^{22}$ In our theoretical model, we obtained a localized radical on one of the ligands for the singly reduced complex, as discussed below.

The redox chemistry of $[\mathrm{Pd}(\mu-\mathrm{OH})(\mathrm{pdp})]_{2}$ was further investigated by spectroelectrochemical methods (Figure 6).

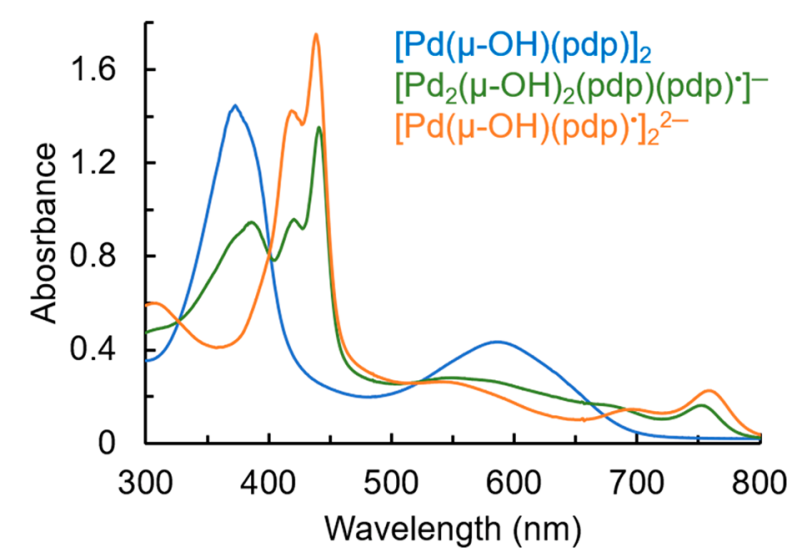

Figure 6. Spectral changes observed upon reduction of $[\operatorname{Pd}(\mu$ $\mathrm{OH})(\mathrm{pdp})]_{2}$ (blue trace) (7:3 v/v DMF: $\mathrm{CH}_{2} \mathrm{Cl}_{2}, 0.1 \mathrm{M}\left(\mathrm{NBu}_{4}\right)-$ $\left.\left(\mathrm{PF}_{6}\right)\right)$ by controlled potential electrolysis to produce the oneelectron reduction product at $-1.00 \mathrm{~V}$ (green trace) and then the two-electron reduction product at $-1.30 \mathrm{~V}$ (orange trace).

Upon controlled potential electrolysis at $-1.00 \mathrm{~V}$, the first reduction is accompanied by a decrease in the main absorption bands (372 and $585 \mathrm{~nm}$ ) with concurrent appearance of transitions at 441, 675, and $752 \mathrm{~nm}$. The presence of lowintensity, near-IR bands in the monoanionic complex is consistent with intraligand $\pi-\pi$ charge-transfer transitions associated with oligopyrrolic radicals, as previously reported. $^{22-24,44}$ Furthermore, the intensity of these bands increases upon generation of the doubly reduced species by electrolysis at $-1.3 \mathrm{~V}$, with minor wavelength shifts (to 439, 695 , and $758 \mathrm{~nm}$ ), suggesting the formation of a dianionic diradical.
The reduction of $[\mathrm{Pd}(\mu-\mathrm{OH})(\mathrm{pdp})]_{2}$ by chemical methods was investigated using cobaltocene $\left(\mathrm{CoCp}_{2}\right)$ in dichloromethane solutions. Anaerobic addition of either 1 or 2 equiv of $\mathrm{CoCp}_{2}$ at room temperature led to the rapid formation of green ( 1 equiv) or orange ( 2 equiv) solutions, with absorption spectra identical to those of the electrochemically generated products. Exposure of the reduced species to air resulted in reoxidation to the neutral complex $[\mathrm{Pd}(\mu-\mathrm{OH})(\mathrm{pdp})]_{2}$ along with partial decomposition as monitored via absorption spectroscopy (Figure S12).

The doubly reduced product was isolated from the reaction mixture by precipitation with pentane to afford a brown solid, and $\mathrm{X}$-ray quality crystals were grown from a layered solution of $\mathrm{CH}_{2} \mathrm{Cl}_{2}$ /pentane at $-20{ }^{\circ} \mathrm{C}$ under a nitrogen atmosphere. The molecular structure obtained for these crystals (Figures 7

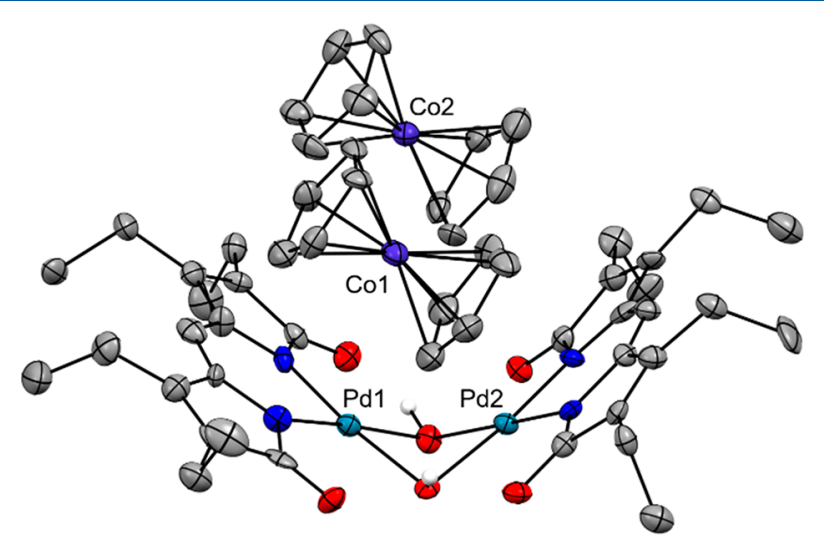

Figure 7. Crystal structure of $\left[\mathrm{CoCp}_{2}\right]_{2}\left[\mathrm{Pd}(\mu-\mathrm{OH})(\mathrm{pdp})^{\bullet}\right]_{2}$ showing a partial labeling scheme. Carbon-bound hydrogen atoms and solvent molecules are omitted for clarity. Non-hydrogen atoms are displayed as thermal displacement ellipsoids set at the $50 \%$ probability level. CCDC: 2077678.

and S13) reveals the presence of two cobaltocenium counterions, thus confirming the successful formation of the two-electron reduction product. Readily apparent upon comparison to the neutral dimer is the increase in folding across the bridged hydroxo ligands: for instance, the angle between the two palladium(II) coordination planes contracts from $159^{\circ}$ to $122^{\circ}$ (Figure S14). The bonds between palladium centers and nitrogen/oxygen donors show slight elongation upon reduction but maintain the square planar geometry expected for a divalent oxidation state. More significant alterations are observed in the dipyrrindione ligand scaffold, particularly elongations of the terminal $\mathrm{C}-\mathrm{O}$ and alternate contractions/elongations of $\mathrm{C}-\mathrm{N}$ bonds on the pyrrolic rings (Table S4). Similar changes to the ligand framework were also observed in palladium(II) tripyrrindione complexes upon one-electron reduction, ${ }^{14}$ as well as in a bis(dipyrrinato)-Pacman dichromium complex after treatment with potassium graphite reductant. ${ }^{45}$ Overall, these changes in the dipyrrindione bond lengths support the assignment of two subsequent one-electron reductions to the ligand frameworks in $\left[\mathrm{CoCp}_{2}\right]_{2}\left[\mathrm{Pd}(\mu-\mathrm{OH})(\mathrm{pdp})^{\bullet}\right]_{2}$.

OLYP-D3/TZ2P calculations were deployed to simulate both monoanionic and dianionic reduction products via the model complexes $\mathrm{Cs}\left[\mathrm{Pd}_{2}(\mu-\mathrm{OH})_{2}(\mathrm{pdp})(\mathrm{pdp})^{\bullet}\right]$ and $\mathrm{Cs}_{2}[\mathrm{Pd}-$ $\left.(\mu-\mathrm{OH})(\mathrm{pdp})^{\bullet}\right]_{2}$, respectively. For the one-electron reduction product, the spin density was found to be localized on one of the dipyrrindione ligands (Figure S15), consistent with the 
spectroelectrochemical data showing the individual absorption profiles of the two ligands in two different redox states (Figure 6). For $\mathrm{Cs}_{2}\left[\mathrm{Pd}(\mu-\mathrm{OH})(\mathrm{pdp})^{\bullet}\right]_{2}$, the bond lengths of the dipyrrindione scaffold were found to be in good agreement with the crystallographic data (Figures $8 \mathrm{a}$ and S16 and Table

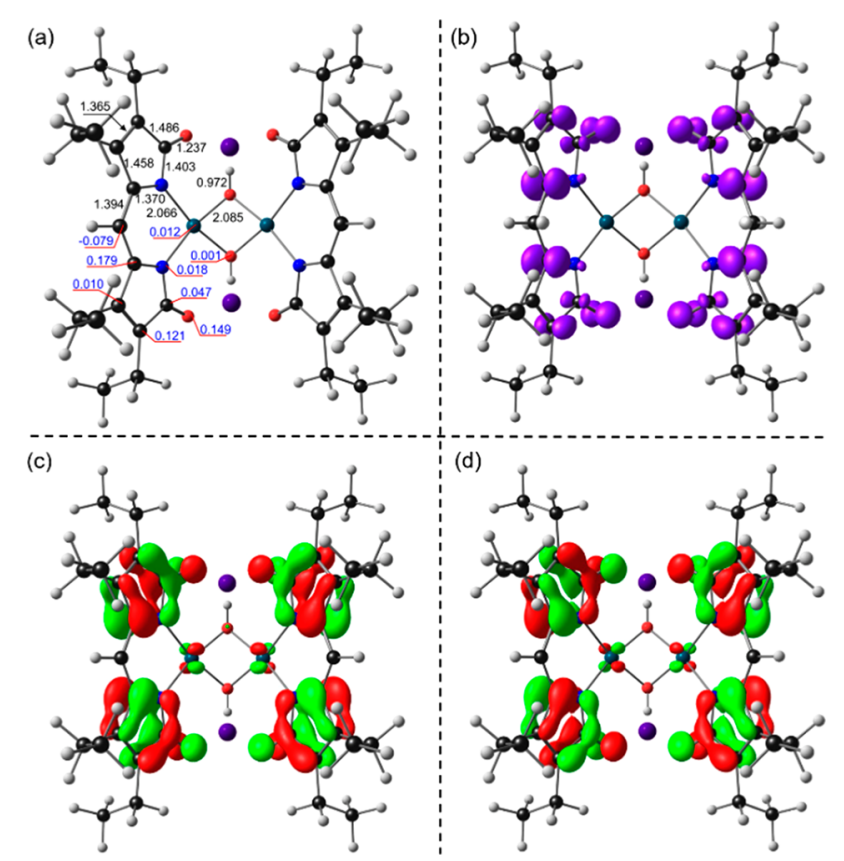

Figure 8. OLYP-D3/TZ2P computational results for diradical species $\mathrm{Cs}_{2}\left[\mathrm{Pd}(\mu-\mathrm{OH})(\mathrm{pdp})^{\bullet}\right]_{2}$ showing (a) selected bond distances $(\AA)$ and Mulliken spin populations in black and blue, respectively, (b) spin densities in violet, and $(c-d)$ SOMOs with phases indicated in red and green.

S6), whereas the calculated structure presents slightly contracted Pd-Pd distance ( $2.790 \AA$ ) and fold angle between dipyrrindione ligand planes (Table S8), likely associated with the size difference between the cobaltocenium and cesium cations. As expected for the product of two ligand-centered reductions, the Mulliken spin density is almost exclusively localized on the two dipyrrindione scaffolds (Figure $8 \mathrm{~b}$ and Table S7). The two SOMOs (Figures 8 and S17) were found to be nearly degenerate and of predominantly ligand character, mirroring the spin density contours.

Further insights into the electronic structure of the reduction products were pursued by X-band and Q-band EPR measurements. The X-band EPR spectrum of the one-electron reduction product is dominated by a single Gaussian line with the width of $0.85 \mathrm{mT}$ between the maximum slope points (Figure 9a, green trace 1). The zero crossing of this line at $B_{0}=$ $336.7 \mathrm{mT}$ corresponds to $g \approx 2.0038$. The Q-band EPR measurement and spectrum simulation (Figure $9 \mathrm{~b}$, trace 1) resulted in a g-tensor with principal components $\left(g_{1}, g_{2}, g_{3}\right)=$ $(2.0059,2.0046,2.0019)$. Such spectroscopic features are characteristic of an organic radical and confirm the ligandbased identity of the observed paramagnetic center. The Xband spectrum was successfully simulated (Figure 8a, dashed black trace 1) based on the g-tensor parameters found from $\mathrm{Q}$ band data.

For a two-electron reduction product featuring two ligandbased spins, a strong magnetic dipole interaction between the unpaired electrons is expected, and indeed, the X-band EPR
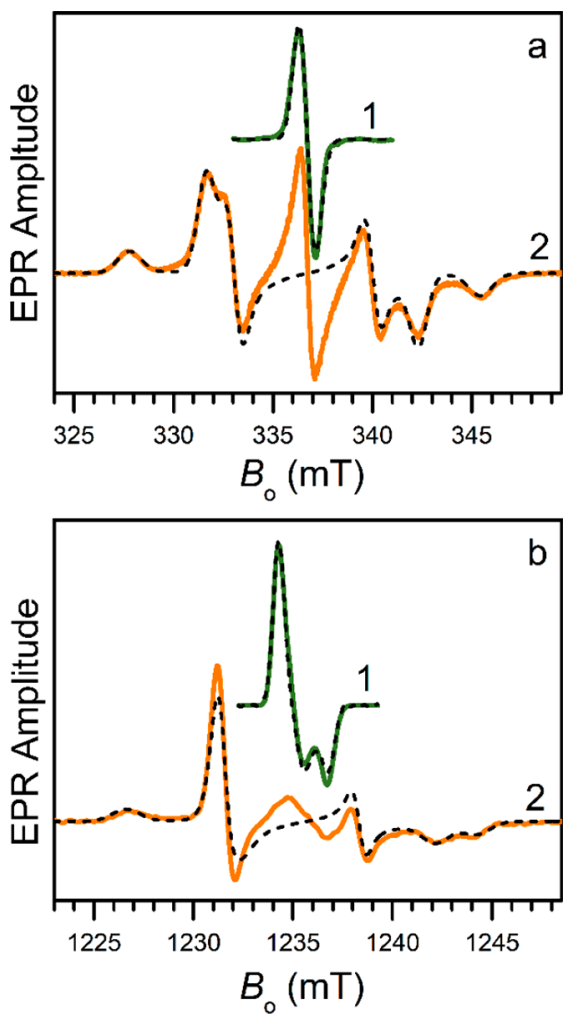

Figure 9. X-band (a) and Q-band (b) EPR spectra of the reduction products of $[\mathrm{Pd}(\mu-\mathrm{OH})(\mathrm{pdp})]_{2}$. Traces 1 and 2 correspond to the reduction with 1 and 2 equiv of $\mathrm{CoCp}_{2}$, respectively. Simulated spectra are shown by black dashed lines. The simulation parameters are as follows: monoanionic complex g-tensor, $\left(g_{1}, g_{2}, g_{3}\right)=(2.0059$, 2.0046, 2.0019); dianionic complex g-tensor, $\left(g_{x}, g_{y}, g_{z}\right)=(2.0045$, $2.0047,2.0022)$ and D-tensor, $\left(D_{x}, D_{y}, D_{z}\right)=(-330,130,200) \mathrm{MHz}$. Experimental conditions and individual line widths used in the simulations are detailed in the Experimental Section.

spectrum (Figure 9a, orange trace 2) shows the characteristic features of a rhombic dipolar coupling. Notably, the spectrum is not exactly symmetric with respect to the central line that corresponds to a residual singly reduced complex. As confirmed by the Q-band spectra (Figure 9b, orange trace $2)$, this asymmetry is caused by the g-factor anisotropy. The spectra were simulated successfully (Figure 9, black dashed traces $)$ using a dipole interaction tensor $\left(D_{x}, D_{y}, D_{z}\right)=(-330$, $130,200) \mathrm{MHz}$ aligned with the g-tensor $\left(g_{x}, g_{y}, g_{z}\right)=(2.0045$, $2.0047,2.0022)$. An analysis based on the spin density distributions predicted by DFT calculations shows (Table S7 and Figure S17) that the principal axis z coincides with the $C_{2}$ symmetry axis of the dimeric complex (which has an overall $C_{2 v}$ symmetry); axis $x$ points in the Pd-to-Pd direction, and axis $y$ is parallel to the line joining the bridging oxygen atoms (Figure S19). This analysis also indicates that the angle between the ligand planes in the dianionic complex in solution is apparently close to $101.6^{\circ}$ as observed in the crystal structure (Figure 7).

From the EPR temperature dependence at cryogenic temperatures (Figure S20), the exchange coupling between the unpaired electrons in the dianionic complex was estimated as $J=-1.75 \pm 0.35 \mathrm{~cm}^{-1}(-2.5 \pm 0.5 \mathrm{~K})$, thus indicating a weak antiferromagnetic exchange interaction. Although the ground state is singlet, the $J$-value is small, and at high 
temperatures $(k T \gg J)$, about $75 \%$ of the complexes are in the triplet state.

As an additional corroboration of the triplet state assignment, we have observed the half-field $\Delta M=2 \mathrm{EPR}$ transition for the dianionic complex (see Figure S21). Collectively, the EPR data have fully confirmed the assignment of $[\operatorname{Pd}(\mu$ $\left.\mathrm{OH})(\mathrm{pdp})^{\bullet}\right]_{2}{ }^{2-}$ as a diradical delocalized on the dipyrrindione ligands.

\section{CONCLUSIONS}

The coordination and redox chemistry of tetraethyl dipyrrindione, also known as propentdyopent, was investigated in heteroleptic palladium complexes. The bis(aqua) $\mathrm{Pd}(\mathrm{II})$ dipyrrindione complex readily undergoes a deprotonationdriven dimerization in the presence of water to give a hydroxobridged binuclear complex. The dimerization is accompanied by a $40 \mathrm{~nm}$ redshift in the visible absorption spectrum and is reversible upon addition of stoichiometric amounts of protic acid. The binuclear $\mu$-hydroxo complex maintains the reversible ligand-centered redox chemistry of prior mononuclear dipyrrindione complexes and undergoes two quasireversible one-electron reduction events. Chemical reduction of this binuclear complex by cobaltocene led to the doubly reduced product. A detailed analysis by crystallography, EPR spectroscopy, and DFT calculations confirmed the formation of a dianionic diradical species, wherein two unpaired electrons are coupled by a weak antiferromagnetic exchange interaction. The weak exchange coupling $(J \approx-2.5 \mathrm{~K})$ results in a predominantly triplet spin state at our usual measurement temperatures of 77 or $296 \mathrm{~K}$ (room temperature). In addition, the dipolar interaction parameters obtained by EPR experiments are consistent with the folded structure observed in the solid state, possibly featuring a $d^{8}-d^{8}$ interaction between the metal centers. The effects of different metal ions and bridging ligands on the geometry and spin interactions of binuclear dipyrrindione complexes will be the subject of upcoming studies. This work demonstrates conclusively the stabilization of unpaired spins on the compact bidentate scaffold of dipyrrindione ligands, thus enhancing the scope of the large family of dipyrrins widely employed in catalysis, imaging, and materials science.

\section{EXPERIMENTAL SECTION}

Materials and Methods. The tetraethyl dipyrrin-1,9-dione methanol adduct ( $\mathrm{Hpdp} \cdot \mathrm{MeOH})^{46}$ and palladium(II) acetylacetonate $\left(\mathrm{Pd}(\mathrm{acac})_{2}\right)^{47}$ were prepared as previously reported. Dichloromethane $\left(\mathrm{CH}_{2} \mathrm{Cl}_{2}\right)$, dimethylformamide (DMF), and pentane were dried by passage through a solvent purifier. All other commercial reagents were used without further purification. NMR spectra were recorded on a Bruker Advance-III $400 \mathrm{MHz}$ and a Bruker NEO-500 $\mathrm{MHz}$ NMR spectrometer at the NMR Spectroscopy Facility of the Department of Chemistry and Biochemistry. UV-visible spectra were obtained at ambient temperature using an Agilent $8453 \mathrm{UV}-$ vis spectrophotometer. High-resolution mass spectra (HRMS) via electrospray ionization (ESI) methods were obtained at the University of Arizona Analytical \& Biological Mass Spectrometry Core Facility. Elemental analyses were performed by NuMega Resonance Laboratories in San Diego, CA.

Synthetic Procedures. $\left[\mathrm{Pd}\left(\mathrm{H}_{2} \mathrm{O}\right)_{2}(\mathrm{pdp})\right]\left[\mathrm{BF}_{4}\right] . \mathrm{Hpdp} \cdot \mathrm{MeOH}(8.5$ $\mathrm{mg}, 0.027 \mathrm{mmol})$ and $\mathrm{Pd}(\mathrm{acac})_{2}(8.1 \mathrm{mg}, 0.027 \mathrm{mmol})$ were dissolved in $\mathrm{CH}_{2} \mathrm{Cl}_{2}(10 \mathrm{~mL})$, and $\mathrm{HBF}_{4}(10 \mu \mathrm{L}, 48 \%$ aqueous solution) was added to the reaction mixture; the mixture was stirred at room temperature for $3 \mathrm{~h}$. Upon reaction completion, as determined through UV-visible absorption spectroscopy, the solvent was removed in vacuo, and the red solid was purified by crystallization from a layered solution of $\mathrm{CH}_{2} \mathrm{Cl}_{2}$ and pentane to afford $\left[\mathrm{Pd}\left(\mathrm{H}_{2} \mathrm{O}\right)_{2}(\mathrm{pdp})\right]\left[\mathrm{BF}_{4}\right]$ as a red crystalline solid $(6.0 \mathrm{mg}, 43 \%) .{ }^{1} \mathrm{H}$ $\operatorname{NMR}\left(500 \mathrm{MHz}, \mathrm{CDCl}_{3}\right): \delta 6.66(\mathrm{~s}, 4 \mathrm{H}), 5.87(\mathrm{~s}, 1 \mathrm{H}) 2.54(\mathrm{q}, J=$ $7.7 \mathrm{~Hz}, 4 \mathrm{H}), 2.35(\mathrm{q}, J=7.6 \mathrm{~Hz}, 4 \mathrm{H}), 1.21(\mathrm{t}, J=7.7 \mathrm{~Hz}, 6 \mathrm{H}), 1.13$ $(\mathrm{t}, J=7.6 \mathrm{~Hz}, 6 \mathrm{H}) \cdot{ }^{13} \mathrm{C}$ NMR $\left(125 \mathrm{MHz}, \mathrm{CDCl}_{3}\right): \delta 185.29,168.78$, $149.90,141.85,94.92,17.87,17.59,14.27,13.16$. UV-vis $\left(\mathrm{CH}_{2} \mathrm{Cl}_{2}\right)$ $\lambda_{\max }(\varepsilon): 382(17,400), 402(16,000), 545\left(6,500 \mathrm{M}^{-1} \mathrm{~cm}^{-1}\right)$. HRMS$\mathrm{ESI}^{+}(\mathrm{m} / z):[\mathrm{M}]^{+}$calcd. for $\left[\mathrm{C}_{17} \mathrm{H}_{25} \mathrm{~N}_{2} \mathrm{O}_{4} \mathrm{Pd}\right], 427.0849$; found, 427.0845. Anal. Calcd for $\left[\mathrm{C}_{17} \mathrm{H}_{25} \mathrm{~N}_{2} \mathrm{O}_{4} \mathrm{BF}_{4} \mathrm{Pd}\right]: \mathrm{C}, 39.7 ; \mathrm{H}, 4.9 ; \mathrm{N}$, 5.4\%. Found: $\mathrm{C}, 39.8 ; \mathrm{H}, 4.5 ; \mathrm{N}, 5.5 \%$.

$[\mathrm{Pd}(\mu-\mathrm{OH})(\mathrm{pdp})]_{2 \cdot}\left[\mathrm{Pd}\left(\mathrm{H}_{2} \mathrm{O}\right)_{2}(\mathrm{pdp})\right]\left[\mathrm{BF}_{4}\right](7.6 \mathrm{mg}, 0.0148 \mathrm{mmol})$ was dissolved in $\mathrm{CH}_{2} \mathrm{Cl}_{2}(15 \mathrm{~mL})$ and shaken with deionized water $(20 \mathrm{~mL})$ in a separatory funnel until the organic layer fully converted from red to blue. The organic layer was further washed with brine and dried over $\mathrm{Na}_{2} \mathrm{SO}_{4}$, and the solvent was removed in vacuo. The resulting blue solid was purified by crystallization from a layered solution of $\mathrm{CH}_{2} \mathrm{Cl}_{2}$ and pentane to afford $[\mathrm{Pd}(\mu-\mathrm{OH})(\mathrm{pdp})]_{2}$ as a blue crystalline solid $(5.3 \mathrm{mg}, 88 \%) .{ }^{1} \mathrm{H}$ NMR $\left(500 \mathrm{MHz} \mathrm{CDCl}_{3}\right): \delta$ $5.55(\mathrm{~s}, 2 \mathrm{H}), 3.07(\mathrm{~s}, 2 \mathrm{H}), 2.47(\mathrm{q}, J=7.7 \mathrm{~Hz}, 8 \mathrm{H}), 2.33(\mathrm{q}, J=7.6$ $\mathrm{Hz}, 8 \mathrm{H}), 1.14(\mathrm{t}, J=7.7 \mathrm{~Hz}, 12 \mathrm{H}), 1.07(\mathrm{t}, J=7.6 \mathrm{~Hz}, 12 \mathrm{H}) .{ }^{13} \mathrm{C}$ NMR $\left(125 \mathrm{MHz}, \mathrm{CDCl}_{3}\right): \delta 182.04,167.82,148.04,139.85,91.66$, $17.85,17.39,14.69,13.70$. UV-vis $\left(\mathrm{CH}_{2} \mathrm{Cl}_{2}\right) \lambda_{\max }(\varepsilon): 372(42,600)$, $585\left(12,400 \mathrm{M}^{-1} \mathrm{~cm}^{-1}\right)$. HRMS-ESI ${ }^{+}(\mathrm{m} / z):[\mathrm{M}+\mathrm{Na}]^{+}$calcd. for $\left[\mathrm{C}_{34} \mathrm{H}_{44} \mathrm{~N}_{4} \mathrm{O}_{6} \mathrm{Pd}_{2} \mathrm{Na}\right], 841.1227$; found, 841.1237. Anal. Calcd Ffor $\left[\mathrm{C}_{34} \mathrm{H}_{44} \mathrm{~N}_{4} \mathrm{O}_{6} \mathrm{Pd}_{2}\right]$ : C, 49.9; H, 5.4; N, 6.8\%. Found: C, 49.8; H, 5.1; $\mathrm{N}, 6.9 \%$.

$[\mathrm{CoCp}]_{2}\left[\mathrm{Pd}(\mu-\mathrm{OH})(\mathrm{pdp})^{\bullet}\right]_{2} . \quad[\mathrm{Pd}(\mu-\mathrm{OH})(\mathrm{pdp})]_{2}(7.8 \mathrm{mg}, 0.0095$ $\mathrm{mmol})$ was dissolved in $\mathrm{CH}_{2} \mathrm{Cl}_{2}(1.5 \mathrm{~mL})$ in a glovebox. $\mathrm{CoCp}_{2}(5.2$ $\mathrm{mg}, 0.0275 \mathrm{mmol})$ reductant was dissolved in $\mathrm{CH}_{2} \mathrm{Cl}_{2}(2.0 \mathrm{~mL})$ to give a $13.75 \mathrm{mM}$ stock solution, $1.40 \mathrm{~mL}(0.01925 \mathrm{mmol}, 2$ equiv $)$ of which were added to the solution of $[\mathrm{Pd}(\mu-\mathrm{OH})(\mathrm{pdp})]_{2}$. After $3 \mathrm{~min}$ of stirring, pentane was added to the reaction mixture to form a brown precipitate. The brown solid was isolated via vacuum filtration and washed with additional pentane to afford $\left[\mathrm{CoCp}_{2}\right]_{2}[\mathrm{Pd}(\mu-\mathrm{OH})-$ $\left.(\mathrm{pdp})^{\bullet}\right]_{2}(8.0 \mathrm{mg}, 70 \%)$. Anal. Calcd for $\left[\mathrm{C}_{54} \mathrm{H}_{63} \mathrm{~N}_{4} \mathrm{O}_{6} \mathrm{Pd}_{2} \mathrm{Co}_{2}\right.$. $\left.1.5 \mathrm{CH}_{2} \mathrm{Cl}_{2}\right]: \mathrm{C}, 50.4 ; \mathrm{H}, 5.1 ; \mathrm{N}, 4.2 \%$. Found: $\mathrm{C}, 50.5 ; \mathrm{H}, 4.9 ; \mathrm{N}$, $4.2 \%$.

X-ray Diffraction Analysis. The single crystal X-ray diffraction measurements were performed at the XRD facility of the University of Arizona, Department of Chemistry and Biochemistry, on a Bruker Kappa APEX II Duo diffractometer equipped APEX II CCD area detector, four-circle kappa goniometer, and an Oxford Cryostream low-temperature system. The data collection was performed at $100 \mathrm{~K}$, using the Mo $\mathrm{K} \alpha$ radiation $(\lambda=0.71073 \AA)$. During the measurements, the instrument was controlled by the APEX2 software package (Bruker AXS Inc., Madison, WI, 2007). The absorption correction was done using a multiscan method implemented in SADABS (Sheldrick, G. M.; University of Göttingen, Germany, 1997).

The crystal structures were solved and refined using the SHELX package ${ }^{48}$ called from the Olex2 ${ }^{49}$ GUI. All non-H atoms were located in the Fourier map and were refined anisotropically. The carbonbound hydrogen atoms were calculated in ideal positions with isotropic displacement parameters set to $1.2 U_{\mathrm{eq}}$ of the attached atom ( $1.5 U_{\text {eq }}$ for methyl hydrogen atoms); their positions were then refined using a riding model. The relevant experimental and structure refinement details are available in Table $S 2$.

Structure Refinement of $\left[\mathrm{Pd}\left(\mathrm{H}_{2} \mathrm{O}\right)_{2}(p d p)\right]\left[\mathrm{BF}_{4}\right]$. Crystals grew as red plates by slow diffusion of hexanes into a solution of $\mathrm{CH}_{2} \mathrm{Cl}_{2}$ at room temperature. Data were solved and refined in the triclinic space group $P-1$. The asymmetric unit cell contained one complex. Q-peaks for the hydrogen-bound $\mathrm{O}-\mathrm{H}$ protons were located in the Fourier map, and hydrogens were assigned to those positions and refined. The four fluorine atoms (F1, F2, F3, and F4) of the tetrafluoroborate anion were found to be disordered by a rotational distribution around the boron atom. The disorder was modeled by a distribution over two positions to provide a stable refinement. The highest residual Fourier peak found in the model was $+1.70 e \AA^{-3}$ approximately $0.88 \AA$ from $\mathrm{F} 3 \mathrm{~A}$, and the deepest Fourier hole was -0.86 e $\AA^{-3}$ approximately $0.75 \AA$ from F4. 
Structure Refinement of $[\mathrm{Pd}(\mu-\mathrm{OH})(p d p)]_{2}$. Crystals grew as red plates by slow diffusion of hexanes into $\mathrm{CH}_{2} \mathrm{Cl}_{2}$ at room temperature. Data were solved and refined in the triclinic space group $P$-1. The asymmetric unit cell contained three complexes. Q-peaks for hydrogen-bound $\mathrm{O}-\mathrm{H}$ protons were located in the Fourier map, and hydrogens were assigned to those positions and refined. The highest residual Fourier peak found in the model was $+0.98 e \AA^{-3}$ approximately $0.89 \AA$ from $\mathrm{Pd} 1 \mathrm{C}$, and the deepest Fourier hole was -0.58 e $\AA^{-3}$ approximately $0.74 \AA$ from $\mathrm{Pd} 2 \mathrm{C}$.

Structure Refinement of $\left[\mathrm{CoCp}_{2}\right]_{2}\left[\mathrm{Pd}(\mu-\mathrm{OH})(p d p)^{\bullet}\right]_{2}$. Crystals grew as brown-orange plates by slow diffusion of pentane into $\mathrm{CH}_{2} \mathrm{Cl}_{2}$ at $-20^{\circ} \mathrm{C}$. Data were solved and refined in the orthorhombic space group $P 2_{1} 2_{1} 2_{1}$. The highest residual Fourier peak found in the model was $+1.05 e \AA^{-3}$ approximately $1.29 \AA$ from O6, and the deepest Fourier hole was $-0.84 e \AA^{-3}$ approximately $0.87 \AA$ from $\mathrm{Co} 2$. The hydrogen atoms on bridging oxygens $\mathrm{O} 5$ and $\mathrm{O} 6$ were restrained to bond lengths of $1.00 \AA$ using DFIX.

Computational Methods. DFT calculations with full geometry optimizations were carried out with the ADF 2018 program system. ${ }^{50}$ A variety of exchange-correlation functionals were tested; the results quoted are those for OLYP, ${ }^{51,52}$ one of the better generalized gradient approximations that we have tested extensively on a variety of transition-metal-containing systems, ${ }^{53-55}$ augmented with Grimme's D3 ${ }^{56}$ dispersion corrections. All-electron Slater-type triple- $z$ plus double polarization (STO-TZ2P) basis sets were used throughout. Point group symmetry was exploited, both in the interest of greater insight and to calculate electronic states with different orbital occupancies. Key results were checked against other pure, hybrid, and range-separated functionals and found to be stable.

Electrochemical Measurements. Cyclic voltammograms were performed on a Gamry Reference 600 potentiostat utilizing a singlecompartment cell with three electrodes: a glassy carbon working electrode, a platinum wire auxiliary electrode, and a $\mathrm{Ag} / \mathrm{AgCl}$ quasireference electrode. Measurements were performed at ambient temperature under an inert argon atmosphere in $\mathrm{CH}_{2} \mathrm{Cl}_{2}$ containing $0.1 \mathrm{M}\left(\mathrm{NBu}_{4}\right)\left(\mathrm{PF}_{6}\right)$ (triply recrystallized) as a supporting electrolyte. Sample concentrations were 1-2 $\mathrm{mM}$, and all electrochemical data were internally referenced to the ferrocene/ferrocenium couple (set at $0.00 \mathrm{~V})$. Spectroelectrochemical measurements were performed using a three-electrode electrochemical quartz cell with a $1.0 \mathrm{~mm}$ path length, a $\mathrm{Au}$ gauze working electrode, $\mathrm{Ag}$ wire quasi-reference electrode, and a $\mathrm{Pt}$ wire counter electrode. The complex was dissolved in 70:30 (v/v) DMF: $\mathrm{CH}_{2} \mathrm{Cl}_{2}$ containing 0.1 $\mathrm{M}\left(\mathrm{NBu}_{4}\right)\left(\mathrm{PF}_{6}\right)$.

EPR Measurements and Simulations. The EPR measurements were performed at two microwave $(\mathrm{mw})$ bands: $\mathrm{X}(\sim 9.5 \mathrm{GHz})$ and $\mathrm{Q}$ $(\sim 34 \mathrm{GHz})$. In the X-band experiments, a continuous-wave EPR spectrometer Elexsys E500 (Bruker Biospin) equipped with a rectangular $\mathrm{TE}_{102}$ resonator was used with experimental conditions as follows: mw frequency, $9.441 \mathrm{GHz}$; mw power, $20 \mu \mathrm{W}$; magnetic field modulation amplitude, $0.2 \mathrm{mT}$. The measurement temperature of $77 \mathrm{~K}$ was achieved by using liquid nitrogen in a finger dewar.

The Q-band measurements were performed on a home-built pulsed EPR spectrometer ${ }^{57}$ equipped with a cylindrical $\mathrm{TE}_{011}$ resonator and a helium gas flow cryostat (CF935, Oxford Instruments). The EPR spectra were obtained by taking a numerical first derivative of electron spin echo (ESE) field sweep spectra. Experimental conditions: $\mathrm{mw}$ frequency, $34.644 \mathrm{GHz}$; mw pulse durations, 140 and $250 \mathrm{~ns}$; time interval $\tau$ between the pulses, $350 \mathrm{~ns}$; boxcar integration gate, $150 \mathrm{ns;}$ measurement temperature, $15 \mathrm{~K}$.

The numerical simulations of the EPR spectra were performed using custom software based on the exact diagonalization of the spin Hamiltonian. In the simulations of the spectrum of the dianionic complex, the $C_{2 v}$ symmetry was taken into account. This symmetry determines the directions of the magnetic axes with respect to the complex (along the $C_{2}$ axis, along the line joining the bridging oxygen atoms, and along the line joining the Pd ions) and requires that the $\mathrm{g}$ and D-tensors are coaxial. The spectroscopic parameters resulting from the simulations are as follows. For the one-electron reduction product, the g-tensor is $\left(g_{1}, g_{2}, g_{3}\right)=(2.0059,2.0046,2.0019)$. The individual line widths used are $\left(\delta B_{1}, \delta B_{2}, \delta B_{3}\right)=(0.75,0.75,0.75) \mathrm{mT}$ for the X-band simulation and $\left(\delta B_{1}, \delta B_{2}, \delta B_{3}\right)=(0.5,0.8,0.65) \mathrm{mT}$ for the Q-band simulation. The simulation parameters for the 2electron reduction product are g-tensor, $\left(g_{x}, g_{y}, g_{z}\right)=(2.0045,2.0047$, 2.0022); D-tensor, $\left(D_{x}, D_{y}, D_{z}\right)=(-330,130,200) \mathrm{MHz}$; individual line widths for X-band, $\left(\delta B_{x}, \delta B_{y}, \delta B_{z}\right)=(1.27,0.7,0.85) \mathrm{mT}$; individual line widths for Q-band, $\left(\delta B_{x}, \delta B_{y}, \delta B_{z}\right)=(1.4,0.6,1.4) \mathrm{mT}$.

\section{ASSOCIATED CONTENT}

\section{(s) Supporting Information}

The Supporting Information is available free of charge at https://pubs.acs.org/doi/10.1021/acs.inorgchem.1c01691.

Optical absorption data, NMR data, X-ray crystallography data, electrochemical data, computational details, EPR analysis data, and supporting figures and tables (PDF)

\section{Accession Codes}

CCDC 2077676-2077678 contain the supplementary crystallographic data for this paper. These data can be obtained free of charge via www.ccdc.cam.ac.uk/data_request/cif, or by emailing data request@ccdc.cam.ac.uk, or by contacting The Cambridge Crystallographic Data Centre, 12 Union Road, Cambridge CB2 1EZ, UK; fax: +44 1223336033.

\section{AUTHOR INFORMATION}

\section{Corresponding Authors}

Abhik Ghosh - Department of Chemistry, UiT - The Arctic University of Norway, N-9037 Tromsø, Norway; 다이.org/0000-0003-1161-6364; Email: abhik.ghosh@ uit.no

Elisa Tomat - Department of Chemistry and Biochemistry, The University of Arizona, Tucson, Arizona 85721, United States; orcid.org/0000-0002-7075-9501;

Email: tomat@arizona.edu

\section{Authors}

Clayton J. Curtis - Department of Chemistry and Biochemistry, The University of Arizona, Tucson, Arizona 85721, United States; (1) orcid.org/0000-0002-9773-8073

Andrei V. Astashkin - Department of Chemistry and Biochemistry, The University of Arizona, Tucson, Arizona 85721, United States

Jeanet Conradie - Department of Chemistry, University of the Free State, Bloemfontein 9300, Republic of South Africa; Department of Chemistry, UiT - The Arctic University of Norway, N-9037 Tromsø, Norway; 이이.org/00000002-8120-6830

Complete contact information is available at: https://pubs.acs.org/10.1021/acs.inorgchem.1c01691

\section{Notes}

The authors declare no competing financial interest.

\section{ACKNOWLEDGMENTS}

This work was supported by the National Science Foundation (CAREER award CHE-1454047 to E.T.), the Research Council of Norway (Grant No. 262229 to A.G.), and the South African National Research Fund (Grant Nos. 129270 and 132504 to J.C.). The Bruker NEO-500 spectrometer in the University of Arizona Department of Chemistry and Biochemistry NMR Facility was purchased thanks to support from the National Science Foundation (MRI award CHE1920234). 


\section{REFERENCES}

(1) van der Vlugt, J. I. Radical-Type Reactivity and Catalysis by Single-Electron Transfer to or from Redox-Active Ligands. Chem. Eur. J. 2019, 25, 2651-2662.

(2) Demir, S.; Jeon, I.-R.; Long, J. R.; Harris, T. D. Radical LigandContaining Single-Molecule Magnets. Coord. Chem. Rev. 2015, 289290, 149-176.

(3) Ding, B.; Solomon, M. B.; Leong, C. F.; D'Alessandro, D. M. Redox-Active Ligands: Recent Advances towards Their Incorporation into Coordination Polymers and Metal-Organic Frameworks. Coord. Chem. Rev. 2021, 439, 213891.

(4) McGuire, J.; Miras, H. N.; Richards, E.; Sproules, S. Enabling Single Qubit Addressability in a Molecular Semiconductor Comprising Gold-Supported Organic Radicals. Chem. Sci. 2019, 10, 14831491.

(5) Stillman, M. Formation and Electronic Properties of RingOxidized and Ring-Reduced Radical Species of the Phthalocyanines and Porphyrins. J. Porphyrins Phthalocyanines 2000, 04, 374-376.

(6) Ganguly, S.; Ghosh, A. Seven Clues to Ligand Noninnocence: The Metallocorrole Paradigm. Acc. Chem. Res. 2019, 52, 2003-2014.

(7) Shimizu, D.; Osuka, A. Porphyrinoids as a Platform of Stable Radicals. Chem. Sci. 2018, 9, 1408-1423.

(8) Attar, S.; Balch, A. L.; Van Calcar, P. M.; Winkler, K. Electron Transfer Behavior and Solid State Structures of the Helical Cobalt Complexes of the Open-Chain Tetrapyrrole Ligand, Octaethylbilindione. J. Am. Chem. Soc. 1997, 119, 3317-3323.

(9) Balch, A. L.; Mazzanti, M.; Noll, B. C.; Olmstead, M. M. Geometric and Electronic Structure and Dioxygen Sensitivity of the Copper Complex of Octaethylbilindione, a Biliverdin Analog. J. Am. Chem. Soc. 1993, 115, 12206-12207.

(10) Kochem, A.; Chiang, L.; Baptiste, B.; Philouze, C.; Leconte, N.; Jarjayes, O.; Storr, T.; Thomas, F. Ligand-Centered Redox Activity in Cobalt(II) and Nickel(II) Bis(Phenolate)-Dipyrrin Complexes. Chem. - Eur. J. 2012, 18, 14590-14593.

(11) Shan, W.; Desbois, N.; Pacquelet, S.; Brandès, S.; Rousselin, Y.; Conradie, J.; Ghosh, A.; Gros, C. P.; Kadish, K. M. Ligand Noninnocence in Cobalt Dipyrrin-Bisphenols: Spectroscopic, Electrochemical, and Theoretical Insights Indicating an Emerging Analogy with Corroles. Inorg. Chem. 2019, 58, 7677-7689.

(12) Moutet, J.; Philouze, C.; du Moulinet d'Hardemare, A.; Leconte, N.; Thomas, F. Ni(II) Complexes of the Redox-Active Bis(2-Aminophenyl)Dipyrrin: Structural, Spectroscopic, and Theoretical Characterization of Three Members of an Electron Transfer Series. Inorg. Chem. 2017, 56, 6380-6392.

(13) Pankhurst, J. R.; Bell, N. L.; Zegke, M.; Platts, L. N.; Lamfsus, C. A.; Maron, L.; Natrajan, L. S.; Sproules, S.; Arnold, P. L.; Love, J. B. Inner-Sphere vs. Outer-Sphere Reduction of Uranyl Supported by a Redox-Active, Donor-Expanded Dipyrrin. Chem. Sci. 2017, 8, 108116.

(14) Gautam, R.; Loughrey, J. J.; Astashkin, A. V.; Shearer, J.; Tomat, E. Tripyrrindione as a Redox-Active Ligand: Palladium(II) Coordination in Three Redox States. Angew. Chem., Int. Ed. 2015, 54, 14894-14897.

(15) Bahnmüller, S.; Plotzitzka, J.; Baabe, D.; Cordes, B.; Menzel, D.; Schartz, K.; Schweyen, P.; Wicht, R.; Bröring, M. Hexaethyltripyrrindione (H3Et6tpd): A Non-Innocent Ligand Forming Stable Radical Complexes with Divalent Transition-Metal Ions. Eur. J. Inorg. Chem. 2016, 2016, 4761-4768.

(16) Tomat, E. Coordination Chemistry of Linear Tripyrroles: Promises and Perils. Comments Inorg. Chem. 2016, 36, 327-342.

(17) Gautam, R.; Astashkin, A. V.; Chang, T. M.; Shearer, J.; Tomat, E. Interactions of Metal-Based and Ligand-Based Electronic Spins in Neutral Tripyrrindione $\pi$ Dimers. Inorg. Chem. 2017, 56, 6755-6762.

(18) Gautam, R.; Petritis, S. J.; Astashkin, A. V.; Tomat, E. Paramagnetism and Fluorescence of Zinc(II) Tripyrrindione: A Luminescent Radical Based on a Redox-Active Biopyrrin. Inorg. Chem. 2018, 57, 15240-15246.

(19) Chang, M.-C.; McNeece, A. J.; Hill, E. A.; Filatov, A. S.; Anderson, J. S. Ligand-Based Storage of Protons and Electrons in
Dihydrazonopyrrole Complexes of Nickel. Chem. - Eur. J. 2018, 24, $8001-8008$

(20) Wood, T. E.; Thompson, A. Advances in the Chemistry of Dipyrrins and Their Complexes. Chem. Rev. 2007, 107, 1831-1861.

(21) Nepomnyashchii, A. B.; Cho, S.; Rossky, P. J.; Bard, A. J. Dependence of Electrochemical and Electrogenerated Chemiluminescence Properties on the Structure of BODIPY Dyes. Unusually Large Separation between Sequential Electron Transfers. J. Am. Chem. Soc. 2010, 132, 17550-17559.

(22) Gautam, R.; Chang, T. M.; Astashkin, A. V.; Lincoln, K. M.; Tomat, E. Propentdyopent: The Scaffold of a Heme Metabolite as an Electron Reservoir in Transition Metal Complexes. Chem. Commun. 2016, 52, 6585-6588.

(23) Gautam, R.; Petritis, S. J.; Tomat, E. Redox-Switchable Cyan Fluorescence of a BODIPY Analog Inspired by Propentdyopent Pigments. Eur. J. Inorg. Chem. 2019, 2019, 68-72.

(24) Curtis, C. J.; Tomat, E. Heteroleptic Palladium(II) Complexes of Dipyrrin-1,9-Dione Supported by Intramolecular Hydrogen Bonding. J. Porphyrins Phthalocyanines 2020, 24, 112-120.

(25) Tomat, E. Propentdyopents: Brief History of a Family of Dipyrrolic Pigments. J. Porphyrins Phthalocyanines 2019, 23, 12651272.

(26) Koerner, R.; Olmstead, M. M.; Van Calcar, P. M.; Winkler, K.; Balch, A. L. Carbon Monoxide Production during the Oxygenation of Cobalt Complexes of Linear Tetrapyrroles. Formation and Characterization of $\mathrm{Co}(\mathrm{II})$ (Tetraethylpropentdyopent Anion)2. Inorg. Chem. 1998, 37, 982-988.

(27) Abe, M. Diradicals. Chem. Rev. 2013, 113, 7011-7088.

(28) Sproules, S.; Wieghardt, K. Dithiolene Radicals: Sulfur K-Edge $\mathrm{X}$-Ray Absorption Spectroscopy and Harry's Intuition. Coord. Chem. Rev. 2011, 255, 837-860.

(29) Poddel'sky, A. I.; Cherkasov, V. K.; Abakumov, G. A. Transition Metal Complexes with Bulky 4,6-Di-Tert-Butyl-N-Aryl(Alkyl)-oIminobenzoquinonato Ligands: Structure, EPR and Magnetism. Coord. Chem. Rev. 2009, 253, 291-324.

(30) Broere, D. L. J.; Demeshko, S.; de Bruin, B.; Pidko, E. A.; Reek, J. N. H.; Siegler, M. A.; Lutz, M.; van der Vlugt, J. I. Dinuclear Palladium Complexes with Two Ligand-Centered Radicals and a Single Bridging Ligand: Subtle Tuning of Magnetic Properties. Chem. - Eur. J. 2015, 21, 5879-5886.

(31) Broere, D. L. J.; Plessius, R.; Tory, J.; Demeshko, S.; de Bruin, B.; Siegler, M. A.; Hartl, F.; van der Vlugt, J. I. Localized MixedValence and Redox Activity within a Triazole-Bridged Dinucleating Ligand upon Coordination to Palladium. Chem. - Eur. J. 2016, 22, 13965-13975.

(32) Vicente, J.; Arcas, A. Aqua Palladium Complexes: Synthesis, Properties and Applications. Coord. Chem. Rev. 2005, 249, 11351154.

(33) Guibert, I.; Neibecker, D.; Tkatchenko, I. Stoicheiometric Dimerisation of Methyl Acrylate Mediated by $\mathrm{Pd}(\mathrm{acac})_{2} \cdot \mathrm{HBF}_{4}$ Systems and Its Relevance to the Mechanism of Catalytic Dimerisation of Acrylates (Hacac $\left.=\mathrm{MeCOCH}_{2} \mathrm{COMe}\right)$. J. Chem . Soc., Chem. Commun. 1989, 1850-1852.

(34) Hagiwara, E.; Fujii, A.; Sodeoka, M. Enantioselective Addition of Enol Silyl Ethers to Imines Catalyzed by Palladium Complexes: A Novel Way to Optically Active Acylalanine Derivatives. J. Am. Chem. Soc. 1998, 120, 2474-2475.

(35) Bronner, C.; Baudron, S. A.; Hosseini, M. W.; Strassert, C. A.; Guenet, A.; De Cola, L. Dipyrrin Based Luminescent Cyclometallated Palladium and Platinum Complexes. Dalton Trans. 2010, 39, 180184.

(36) Diaz-Rodriguez, R. M.; Robertson, K. N.; Thompson, A. Classifying Donor Strengths of Dipyrrinato/Aza-Dipyrrinato Ligands. Dalton Trans. 2019, 48, 7546-7550.

(37) Ghosh, A. Transition Metal Spin State Energetics and Noninnocent Systems: Challenges for DFT in the Bioinorganic Arena. JBIC, J. Biol. Inorg. Chem. 2006, 11, 712-724. 
(38) Ryeng, H.; Gonzalez, E.; Ghosh, A. DFT at Its Best: Metalversus Ligand-Centered Reduction in Nickel Hydroporphyrins. J. Phys. Chem. B 2008, 112, 15158-15173.

(39) Conradie, J.; Brothers, P. J.; Ghosh, A. Main-Group-Element Isophlorin Complexes Revisited: The Question of a Subvalent Central Atom. Inorg. Chem. 2019, 58, 4634-4640.

(40) Foroutan-Nejad, C.; Larsen, S.; Conradie, J.; Ghosh, A. Isocorroles as Homoaromatic NIR-Absorbing Chromophores: A First Quantum Chemical Study. Sci. Rep. 2018, 8, 11952.

(41) Conradie, J.; Foroutan-Nejad, C.; Ghosh, A. Norcorrole as a Delocalized, Antiaromatic System. Sci. Rep. 2019, 9, 4852.

(42) Bercaw, J. E.; Durrell, A. C.; Gray, H. B.; Green, J. C.; Hazari, N.; Labinger, J. A.; Winkler, J. R. Electronic Structures of $\mathrm{Pd}(\mathrm{II})$ Dimers. Inorg. Chem. 2010, 49, 1801-1810.

(43) Zanello, P.; Nervi, C.; Fabrizi de Biani, F. Inorganic Electrochemistry; The Royal Society of Chemistry, 2011.

(44) Lecarme, L.; Chiang, L.; Moutet, J.; Leconte, N.; Philouze, C.; Jarjayes, O.; Storr, T.; Thomas, F. The Structure of a One-Electron Oxidized Mn(III)-Bis(Phenolate)Dipyrrin Radical Complex and Oxidation Catalysis Control via Ligand-Centered Redox Activity. Dalton Trans. 2016, 45, 16325-16334.

(45) Carsch, K.; Elder, S. E.; Dogutan, D. K.; Nocera, D. G.; Yang, J.; Zheng, S.-L.; Daniel, T.; Betley, T. A. Syntheses and Solid-State Structures of Two Cofacial (Bis)Dipyrrin Dichromium Complexes in Different Charge States. Acta Crystallogr., Sect. C: Struct. Chem. 2021, 77, 161-166.

(46) Bonnett, R.; Ioannou, S.; Swanson, F. J. Propentdyopents and Related Compounds. Part 4. Propentdyopent-Alkanol Adducts by the Photo-Oxygenation of Pyrromethenones. J. Chem. Soc., Perkin Trans. 1 1989, 1, 711-714.

(47) Hamid, M.; Zeller, M.; Hunter, A. D.; Mazhar, M.; Tahir, A. A. Redetermination of Bis(2,4-Pentanedionato)-Palladium(II). Acta Crystallogr., Sect. E: Struct. Rep. Online 2005, 61, 2181-2183.

(48) Sheldrick, G. M. SHELXT - Integrated Space-Group and Crystal-Structure Determination. Acta Crystallogr., Sect. A: Found. Adv. 2015, 71, 3-8.

(49) Dolomanov, O. V.; Bourhis, L. J.; Gildea, R. J.; Howard, J. A. K.; Puschmann, H. OLEX2: A Complete Structure Solution, Refinement and Analysis Program. J. Appl. Crystallogr. 2009, 42, 339-341.

(50) te Velde, G.; Bickelhaupt, F. M.; Baerends, E. J.; Fonseca Guerra, C.; van Gisbergen, S. J. A.; Snijders, J. G.; Ziegler, T. Chemistry with ADF. J. Comput. Chem. 2001, 22, 931-967.

(51) Handy, N. C.; Cohen, A. Left-Right Correlation Energy. Mol. Phys. 2001, 99, 403-412.

(52) Lee, C.; Yang, W.; Parr, R. G. Development of the ColleSalvetti Correlation-Energy Formula into a Functional of the Electron Density. Phys. Rev. B: Condens. Matter Mater. Phys. 1988, 37, 785789.

(53) Conradie, J.; Ghosh, A. DFT Calculations on the SpinCrossover Complex Fe(Salen)(NO): A Quest for the Best Functional. J. Phys. Chem. B 2007, 111, 12621-12624.

(54) Conradie, J.; Ghosh, A. Electronic Structure of Trigonal-Planar Transition-Metal-Imido Complexes: Spin-State Energetics, SpinDensity Profiles, and the Remarkable Performance of the OLYP Functional. J. Chem. Theory Comput. 2007, 3, 689-702.

(55) Conradie, M. M.; Conradie, J.; Ghosh, A. Capturing the Spin State Diversity of Iron(III)-Aryl Porphyrins: OLYP Is Better than TPSSh. J. Inorg. Biochem. 2011, 105, 84-91.

(56) Grimme, S.; Antony, J.; Ehrlich, S.; Krieg, H. A Consistent and Accurate Ab Initio Parametrization of Density Functional Dispersion Correction (DFT-D) for the 94 Elements H-Pu. J. Chem. Phys. 2010, $132,154104$.

(57) Astashkin, A. V.; Enemark, J. H.; Raitsimring, A. 26.5-40 GHz Ka-Band Pulsed EPR Spectrometer. Concepts Magn. Reson., Part B 2006, 29B, 125-136. 